\title{
Relationship Between Opioid Therapy, Tissue-Damaging Procedures, and Brain Metabolites as Measured by Proton MRS in Asphyxiated Term Neonates
}

\author{
DANILYN M. ANGELES, STEPHEN ASHWAL, NATHANIEL D. WYCLIFFE, CHARLOTTE EBNER, ELBA FAYARD, \\ LAWRENCE SOWERS, AND BARBARA A. HOLSHOUSER
}

\author{
Departments of Physiology and Pharmacology [D.M.A., C.E.], Pediatrics [S.A., E.F.], Radiology [N.D.W., B.A.H.], and Biochemistry \\ [L.S.], Loma Linda University School of Medicine, Loma Linda, California 92350
}

\begin{abstract}
To examine the effects of opioid and tissue-damaging procedures (TDPs) [i.e. procedures performed in the neonatal intensive care unit (NICU) known to result in pain, stress, and tissue damage] on brain metabolites, we reviewed the medical records of 28 asphyxiated term neonates (eight opioid-treated, 20 non-opioid treated) who had undergone magnetic resonance imaging (MRI) and proton magnetic resonance spectroscopy (MRS) within the first month of life as well as eight newborns with no clinical findings of asphyxial injury. We found that lower creatine $(\mathrm{Cr})$, myoinositol (Ins), and $N$-acetylaspartate $(\mathrm{NAA}) /$ choline $(\mathrm{Cho})(p \leq 0.03)$ and higher $\mathrm{Cho} / \mathrm{Cr}$ and glutamate/glutamine (Glx) $\mathrm{Cr}(p \leq 0.02)$ correlated with increased TDP incidence in the first $2 \mathrm{~d}$ of life (DOL). We also found that occipital gray matter (OGM) NAA/Cr was decreased ( $p=0.03)$ and lactate (Lac) was present in a significantly higher amount $(40 \% ; p=0.03)$ in non-opioid-treated neonates compared with opioid-treated neonates. Compared with controls, untreated neonates showed larger changes in more metabolites in basal ganglia (BG), thalami (TH), and OGM with greater significance than treated neonates. Our data suggest that TDPs affect spectral metabolites and that opioids do not cause harm in asphyxiated term neonates exposed to repetitive TDPs in the first 2-4 DOL and may provide a degree of neuroprotection. (Pediatr Res 61: 614-621, 2007)
\end{abstract}

$\mathrm{P}$ erinatal asphyxia is a common cause of neonatal encephalopathy and frequently results in epilepsy, cerebral palsy, and other long-term neurodevelopmental disorders (1). A cascade of biochemical events take place after asphyxia resulting in changes in brain metabolites that can be monitored noninvasively using proton magnetic resonance spectroscopy (MRS). Noninvasive in vivo measurements of NAA, total $\mathrm{Cr}$ [Cr and phosphocreatine (PCr)], Cho-containing compounds, Ins, Glx, and Lac are possible (2). NAA, an amino acid found exclusively in the nervous system, serves primarily as a neuronal marker. $\mathrm{Cr}$, measured as $\mathrm{Cr}$ plus $\mathrm{PCr}$ with proton MRS, is a bioenergetic marker and reflects the energy potential available to neurons and other cells. The Cho peak includes contributions mostly from phosphocholine and its

Received June 21, 2006; accepted January 9, 2007

Correspondence: Danilyn Angeles, Ph.D., Department of Physiology and Pharmacology, Loma Linda University School of Medicine, Loma Linda, CA 92350; e-mail: dangeles@1lu.edu

This investigation was supported by a grant from the National Institute of Nursing Research (NR8116).

DOI: 10.1203/pdr.0b013e318045bde9 products glycerophosphocholine and phosphatidylcholine, which are intermediates in phospholipid metabolism thought to be released during membrane disruption. Ins is a glial marker and an important osmolyte. Glutamate and immediately formed glutamine are the major neurotransmitters for brain excitatory function and are often reported in combination because high spin-coupling makes it difficult to measure them separately. The measurement of Glx provides information about neuronal and glial metabolism and interaction $(2,3)$. Lac and its redox partner pyruvate are the terminal metabolites in glycolysis.

We recently reported that asphyxiated term neonates treated with opioids for pain during the first week of life had significantly less brain injury as assessed by MRI scores as well as better long-term neurologic outcomes (4). To examine the hypothesis that opioids alter brain metabolism in asphyxiated term neonates, we analyzed and compared brain metabolite data in control, opioid-treated, and non-opioid-treated neonates using MRS. The number of exposures to TDPs in the first 4 DOL was correlated with brain metabolite data to examine the hypothesis that exposure to pain and stress alters brain biochemistry by altering brain metabolites. TDPs are those procedures performed in the NICU known to result in pain, stress, and tissue damage (Table 1). Although lifesaving, many of these procedures often result in cardiovascular stress including tachycardia, bradycardia, hypertension, hypotension, and episodes of hypoxemia (5-7).

\section{METHODS}

Patient Data. Medical records of term newborns with asphyxial brain injury were reviewed. Inclusion criteria included MRS and MRI acquired within the first month of life and at least one of the following criteria: (a) 5-min Apgar $\leq 5$, (b) cord umbilical arterial $\mathrm{pH} \leq 7.10$, (c) cord base excess -10 or more, or (d) clinical postasphyxial syndrome (encephalopathy, seizure, intraventricular hemorrhage). Exclusion criteria included proven congenital infection or metabolic disease or central nervous system (CNS) or other major malformations such as cyanotic heart disease and diaphragmatic

Abbreviations: BG, basal ganglia; Cho, choline; $\mathbf{C r}$, total creatine; Glx, glutamate/glutamine; Ins, myoinositol; MRSI, magnetic resonance spectroscopic imaging; NAA, $N$-acetylaspartate; OGM, occipital gray matter; PCPCS, Pediatric Cerebral Performance Category Scale; PCr, phosphocreatine; SVS, single-voxel spectroscopy; TE, echo delay time; TH, thalami; TR, repetition time 
Table 1. TDPS

\section{Endotracheal intubation}

Tracheal suctioning

Peripherally inserted central catheter line placement

Removal of tape from skin

Venipuncture

Intravenous catheter placement

Arterial line placement (umbilical, radial, etc.)

Orogastric or nasogastric tube placement

Lumbar puncture

Heelstick

Intramuscular injections

Urinary catheterization

Chest tube placement

hernia. Control patients were term neonates with no history of asphyxia but who were admitted to the NICU and had undergone MRI and MRS as part of their evaluation for an underlying neurologic condition such as seizures. This study was reviewed and approved by the Loma Linda University Institutional Review Board.

Number of TDPs. A list of TDPs recorded for this study is summarized in Table 1. The frequency with which these procedures occurred in the first 4 DOL was recorded on a data sheet developed by the investigators. This time period was chosen to determine whether a relationship existed between the number of TDPs and brain metabolites at a time when brain $\mathrm{PCr}$ and inorganic phosphate concentrations are decreased $(8,9)$. This period of secondary energy failure is believed to result in additional brain injury after perinatal asphyxia.

Use of opioid analgesics. Patient demographics such as gestational age, birth weight, Apgar scores, initial $\mathrm{pH}, \mathrm{PaO}_{2}$, base excess, and $\mathrm{PaCO}_{2}$ were obtained. Medication administration records, nursing forms, physician's order sheets, and the institution's pharmacy records were reviewed for documentation of administration of opioid analgesics. Neonates who received morphine or fentanyl in the first 4 DOL were compared with asphyxiated neonates who did not receive opioids.

MRI. All studies were performed using a circularly polarized head coil in a conventional 1.5-T whole-body imaging system (Magnetom Vision, Siemens Medical Systems, Erlangen, Germany). Images were acquired and scored using a previously validated scoring system (10). To assess severity of injury in the $\mathrm{BG}$ and watershed (W)-cortical regions, three sequences were used: (1) sagittal and axial T1-weighted (T1W) spin-echo sequences [repetition time (TR)/echo delay time $(\mathrm{TE})=500-600 / 22 \mathrm{~ms}$, four acquisitions (acq), 4 mm thick]; (2) an axial triple spin-echo sequence (TR/TE1/TE2/TE3 = 3000/22/60/120 ms, 1 acq, $4 \mathrm{~mm}$ thick); and (3) a diffusion weighted single-shot echo planar imaging (DWI) sequence (TE $=110 \mathrm{~ms}, 4 \mathrm{~mm}$ thick, $\mathrm{b}$ values $=0,500,1000 \mathrm{~s} / \mathrm{mm}^{2}$ with an apparent diffusion coefficient map. Images were also used for localization and voxel placement for the subsequent MRS study. The proton density-weighted (PDW) image (first echo of the triple spin-echo sequence; TR/TE $=3000 / 22 \mathrm{~ms}$ ) and the T2 weighted $(\mathrm{T} 2 \mathrm{~W})$ image (third echo of triple spin-echo sequence; TR/TE $=3000 / 120$ ) along with the T1W and DWI were evaluated by a neuroradiologist (N.D.W.) and used to assign a BG score, a W score, and a combined BG/W score for each type of image. The MR scoring system used in this study was previously shown to discriminate between good and poor neuromotor and cognitive outcomes at 3 and 12 mo in asphyxiated neonates (10). Scores range from 0 (normal) to 4 or 5 (extensive involvement) in regions evaluated.

MRS. Two-dimensional magnetic resonance spectroscopic imaging (MRSI) using point resolved spectroscopy (PRESS) through the level of the BG and TH and single voxel spectroscopy (SVS) stimulated-echo acquisition mode (STEAM) sequences as well as SVS PRESS in the mid-occipital gray matter were used for metabolite measurements. After manual shimming, the water-suppressed MRSI acquisition was acquired with a TR/TE $=3000 / 144$ $\mathrm{ms}$ in a 10-mm thick axial slab (maximum of $160 \mathrm{~mm}$ field of view, $16 \times 16$ phase encodings, up to 25 voxels $(5 \times 5) /$ volume of interest, nominal voxel volume of 1-2 mL/voxel) through the level of the BG, TH, and temporal white and gray matter as shown in Figure 1. MRSI and SVS PRESS spectra were postprocessed including zero filling to $32 \mathrm{k}, 1-\mathrm{Hz}$ exponential multiplication, Fourier transformation, zero-order phase correction, and baseline correction (Luise, Numaris VB33D, Siemens Medical Solutions) to obtain peak areas for NAA at $2.01 \mathrm{ppm}, \mathrm{Cr}$ (as $\mathrm{Cr}+\mathrm{PCr}$ ) at $3.0 \mathrm{ppm}$, Cho at 3.2 ppm, Lac, if present (identified as an inverted doublet at $1.33 \mathrm{ppm}$ ), and Glx (as $\alpha$-Glx) at $3.75 \mathrm{ppm}$ according to the method of $\mathrm{Pu}$ and colleagues (11). Each spectrum was visually inspected (B.A.H.) for adequate spectral quality. Using voxel-shifting techniques to minimize cerebrospinal fluid contamina-

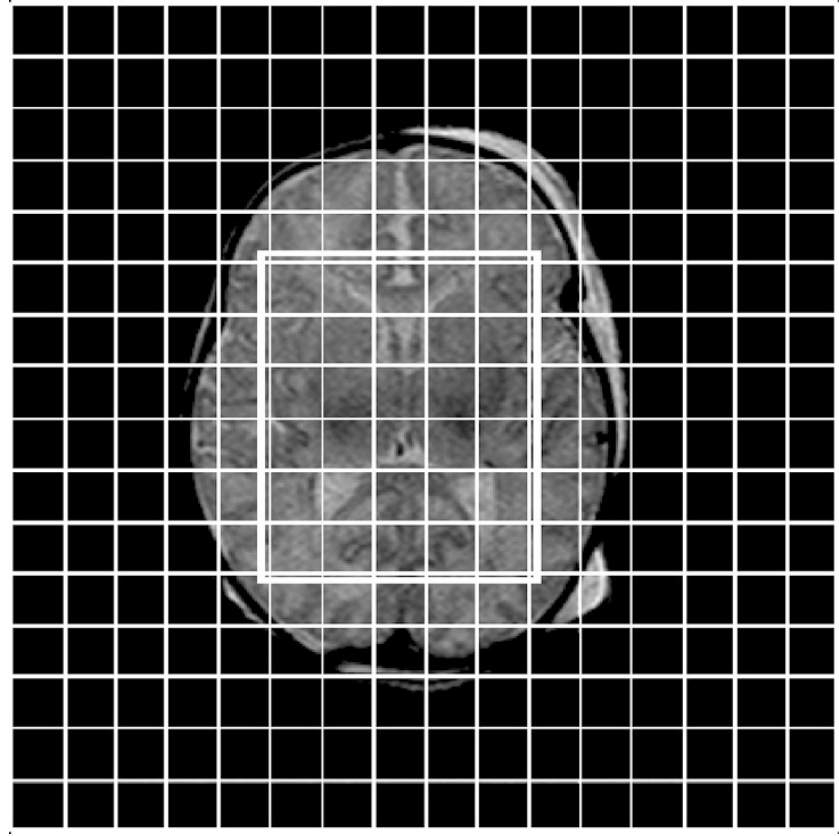

Figure 1. Typical positioning of an MRSI slab at the level of the BG. The bright rectangular box shows the region of interest acquired.

tion and overlap with other regions, voxels were located to obtain four spectra (left and right BG and TH). Peak areas for each metabolite were measured and used to calculate metabolite ratios in each voxel (NAA/Cr, NAA/Cho, Cho/ $\mathrm{Cr}$, and $\mathrm{Lac} / \mathrm{Cr}$ ). Ratios from the left and right side in each region were averaged to obtain mean ratios for the BG and TH. In addition, two singlevoxel proton spectra were acquired with $8-\mathrm{mL}$ volumes in a $\mathrm{W}$ region in the OGM located in a paramedian position across the interhemispheric fissure (Fig. 2 A) using first a short TE STEAM sequence [TR/TE/mixing time (TM) = $3000 / 20 / 13 \mathrm{~ms}, 128 \mathrm{acq}]$ and repeated in the same location with a PRESS sequence $(\mathrm{TR} / \mathrm{TE}=3000 / 144 \mathrm{~ms}, 128 \mathrm{acq})$ after manual localized shimming to achieve water line widths $<8 \mathrm{~Hz}$. A reference spectrum was acquired with identical acquisition parameters and eight acq without water suppression to use for eddy current correction. Quantitative metabolite levels in millimoles $(\mathrm{mM})$ for NAA, Cr, Cho, Lac as a doublet at $1.33 \mathrm{ppm}$ (not inverted at short $\mathrm{TE}$ ), Ins at $3.56 \mathrm{ppm}$, and Glx (as $\beta$ - and $\gamma$-Glx) at a range of 2.0 to $2.5 \mathrm{ppm}$ for each patient were measured for the STEAM acquisition using a linear combination model of in vitro spectra (LCModel) (12), as described in previous publications (13). LCModel is a user-independent fitting routine based on a library of model spectra of individual metabolites at known concentrations that corrects spectral data for actual coil loading by using the transmitter reference amplitude of the MR system to account for system differences between subjects. The metabolite measurements were accepted if the estimated confidence measurement (Cramer-Rao lower bounds) was reported to be $\leq 20 \%$. Metabolite levels were not corrected for residual T2 relaxation effects due to the additional time needed for acquisition. Long repetition times were used to minimize $\mathrm{T} 1$ relaxation time effects. The following metabolite ratios for short TE spectra were calculated from quantitative levels (NAA/Cr, NAA/Cho, Cho/Cr, Ins/Cr, Glx/Cr). Lac presence was recorded for each patient in short TE spectra. In addition, we confirmed Lac presence (as an inverted doublet) using the PRESS TE $=144 \mathrm{~ms}$ spectrum from the identical location.

Long-term neurologic outcome scores. The correlation between brain metabolite levels and long-term outcome also was examined. To determine long-term neurologic outcome, infants were evaluated at discharge and subsequent visits using the Pediatric Cerebral Performance Category Scale (PCPCS), a 6-point outcome scoring system modified for pediatric use from the Glasgow Outcome Scale score (14). The PCPCS quantifies the overall functional and cognitive impairment of neonates and children and has been validated in 1469 pediatric patients after acute CNS injuries (15) and shown to correlate with other measures of psychological outcome (16). The PCPCS was obtained by an experienced pediatric neurologist (S.A.) who was blinded to MRS or opioid utilization. The score includes the following outcomes: 1 for normal: can perform all age-appropriate activities; 2 for mild disability: conscious, alert, and able to interact in most age-appropriate activities and may have a mild neurologic deficit; 3 for moderate disability: conscious, sufficient cerebral function for age-appropriate activities of daily life, but has 

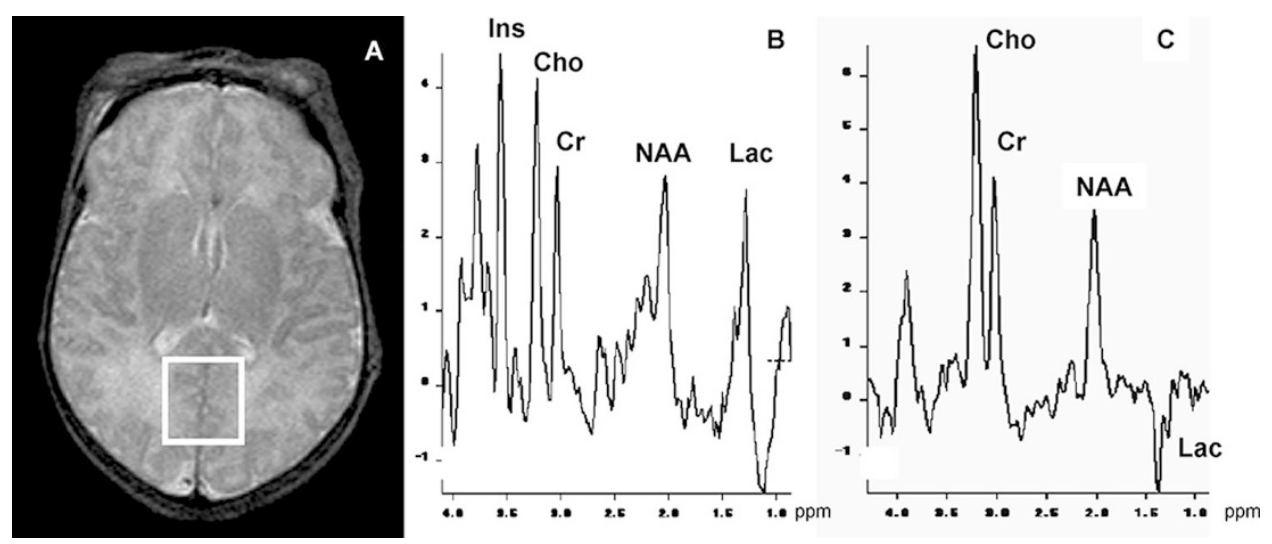

Figure 2. (A) Typical positioning of an SVS acquisition in the mid-OGM. (B) STEAM $(\mathrm{TR} / \mathrm{TE} / \mathrm{TM}=3000 / 20 / 13 \mathrm{~ms})$ from the region illustrated in $A$ in an asphyxiated neonate. $(C)$ Long echo time SVS (PRESS; TR/TE $=3000 / 144 \mathrm{~ms}$ ) in the same region used to confirm Lac presence.

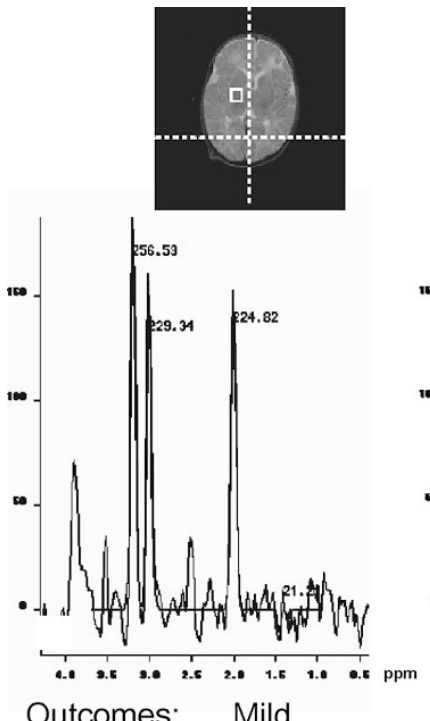

Outcomes: Mild
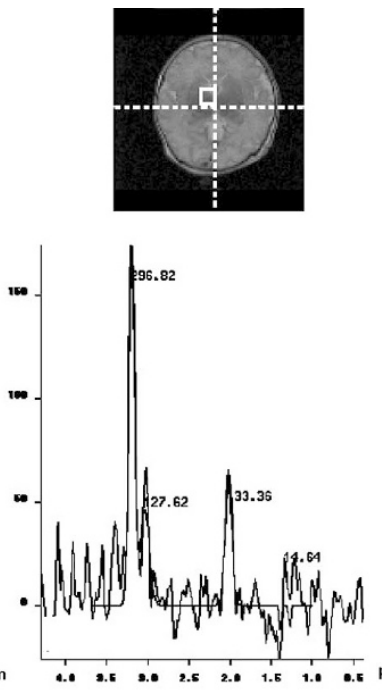

Moderate
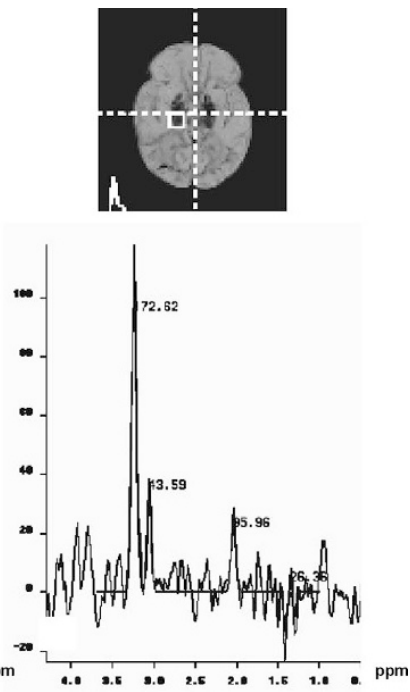

Severe
Figure 3. Spectra from the BG/TH (MRSI; PRESS; TE $=144 \mathrm{~ms}$ ) from neonates with hypoxic-ischemic encephalopathy. significant cognitive impairment; 4 for severe disability: conscious, dependent on others for daily support because of impaired brain function; 5 for persistent vegetative state; and 6 for death.

Statistics. Data were analyzed using one-way analysis of variance (ANOVA) and reported as the mean \pm SEM. We also used the MannWhitney or Kruskal-Wallis test for data that did not fit normal distribution. Fisher's least significant difference (LSD) and Tukey's honestly significant difference (HSD) tests were used to adjust for multiple comparisons. Ordinal data were analyzed using $\chi^{2}$. Correlations coefficients were obtained using a Spearman's $\rho$ analysis. All statistical analyses were performed using SPSS Statistics for Windows Version 10. Differences were considered significant at $p<0.05$.

\section{RESULTS}

General results. Between 2000 and 2005, 28 asphyxiated neonates met our study criteria (eight opioid treated, 20 non-opioid treated). Twenty-six of these neonates were part of a cohort of 52 asphyxiated neonates whose MRI and clinical outcomes were reported previously (4). An additional two asphyxiated neonates who were not part of our previous study but who met study criteria were included in this study. In addition, a group of eight neonates with no history of opioid exposure or clinical examination or MRI findings suggestive of asphyxia were included for comparison. All the control patients had normal outcomes as determined by the PCPCS scores at $10 \pm 4$ mo of age. Table 2 summarizes demographic and clinical characteristics. No significant differences in de- mographic variables were noted between the three groups. The rationale for the clinician's choice to treat or not to treat with opioid analgesia was not well documented in the medical records, although prescription of opioid analgesia seemed to be related to the severity of the infant's illness. Neonates who received opioids had significantly lower 5-min Apgar scores $(p<0.05)$ and significantly larger base deficits $(p<0.05)$ than control neonates (Table 2). Opioid-treated neonates received either continuous morphine at $30-40 \mu \mathrm{g} / \mathrm{kg} / \mathrm{h}$ or fentanyl infusion at $2-5 \mu \mathrm{g} / \mathrm{kg} / \mathrm{h}$ in the first $1-2$ DOL, followed by intermittent (every $2-4 \mathrm{~h}$ as needed) opioid boluses in the next 3-4 DOL or vice versa. Similar to our previously published study (4), we found that opioid-treated neonates in this study had significantly lower MRI scores (i.e. less evidence of injury) than neonates who did not receive opioids (Table 3 ). There were no significant differences between opioid and non-opioid-treated groups with regards to documentation of presence of clinical postasphyxial syndrome (seizures, intraventricular hemorrhage, and multiorgan failure). However, we found that $100 \%$ of opioid-treated neonates received mechanical ventilation versus $53 \%$ of nonopioid treated neonates $(p<$ 0.016).

In this study, we compared MRI scores with brain metabolite data obtained from BG and TH (Table 4) and OGM 
Table 2. Patient demographics and clinical characteristics of control, opioid-treated, and non-opioid-treated neonates who underwent MRS

\begin{tabular}{|c|c|c|c|c|}
\hline & $\begin{array}{l}\text { Control } \\
(n=8)\end{array}$ & $\begin{array}{l}\text { Received opioid } \\
\quad(n=8)\end{array}$ & $\begin{array}{l}\text { No opioid } \\
(n=20)\end{array}$ & $p^{*}$ \\
\hline Birth weight, g & $3519 \pm 251$ & $3681 \pm 294$ & $3056 \pm 133$ & NS \\
\hline Estimated gestational age, wk & $39 \pm 0.4$ & $39 \pm 0.6$ & $39 \pm 0.3$ & NS \\
\hline Birth hospital & $\begin{array}{r}\text { Outborn: } 6(75 \%) \text {; } \\
\text { inborn: } 2(25 \%)\end{array}$ & $\begin{array}{l}\text { Outborn: } 5(63 \%) \text {; } \\
\text { inborn; } 3(37 \%)\end{array}$ & $\begin{array}{l}\text { Outborn: } 17(94 \%) \\
\text { inborn: } 1(6 \%)\end{array}$ & NS \\
\hline Apgar at $1 \mathrm{~min}$ & $5.2 \pm 2$ & $2.38 \pm 0.4$ & $3.3 \pm 0.7$ & NS \\
\hline Apgar at $5 \mathrm{~min}$ & $8.2 \pm 0.6$ & $3.8 \pm 0.5$ & $5.7 \pm 0.6$ & $0.007 \dagger$ \\
\hline Initial $\mathrm{pH}$ & $7.28 \pm 0.11$ & $6.99 \pm 0.08$ & $7.18 \pm 0.06$ & NS \\
\hline Initial $\mathrm{Pco}_{2}, \mathrm{~mm} \mathrm{Hg}$ & $53 \pm 9$ & $66 \pm 13$ & $42 \pm 6$ & NS \\
\hline Initial $\mathrm{BE}, \mathrm{mEq} / \mathrm{L}$ & $2 \pm 8$ & $-17 \pm 3$ & $-11 \pm 2$ & $0.03 \dagger$ \\
\hline Initial $\mathrm{HCO}_{3}, \mathrm{mmol} / \mathrm{L}$ & $24 \pm 2$ & $16.7 \pm 2$ & $15.6 \pm 2$ & NS \\
\hline $\begin{array}{l}\text { No. of patients with moderate to severe } \\
\text { disability (PCPCS score of 3-6) }\end{array}$ & 0 & $2(25 \%) ; 2$ had PCPCS of 3 & $\begin{array}{l}5(25 \%) ; 1 \text { had PCPCS of } 3, \\
2 \text { had PCPCS of } 4, \\
2 \text { had PCPCS of } 6\end{array}$ & NS \\
\hline Lost to follow-up & 0 & 0 & $4(20 \%)$ & NS \\
\hline
\end{tabular}

Opioid- and non-opioid-treated neonates met inclusion criteria for neonatal encephalopathy as described in the text. Mean \pm SEM. Control patients had no documented asphyxia and did not receive opioids. Hgb, hemoglobin; Hct, hematocrit.

*One-way ANOVA, $\chi^{2}$ test for nominal variables.

$\dagger$ Control vs received opioid.

(Table 5). Strong correlations were found between the severity of neuroimaging abnormalities as measured by increased imaging scores and spectroscopic measurements (i.e. reduced NAA/Cho and NAA/Cr; increased $\mathrm{Cho} / \mathrm{Cr}$ and $\mathrm{Glx} / \mathrm{Cr}$ ).

Use of opioids and TDPs in asphyxiated infants. Opioidtreated and non-opioid-treated asphyxiated neonates experienced an average of 15 TDPs in the first DOL (Fig. 4). Control

Table 3. MRI scores*

\begin{tabular}{lcccc}
\hline & $\begin{array}{c}\text { Control } \\
(n=8)\end{array}$ & $\begin{array}{c}\text { Received opioid } \\
(n=8)\end{array}$ & $\begin{array}{c}\text { No opioid } \\
(n=20)\end{array}$ & $p \dagger$ \\
\hline BG & & & & \\
T1W & $0 \pm 0$ & $0.13 \pm 0.13$ & $1.80 \pm 0.41$ & 0.031 \\
PDW & $0 \pm 0$ & $0.00 \pm 0.00$ & $1.70 \pm 0.44$ & 0.012 \\
T2W & $0 \pm 0$ & $0.13 \pm 0.13$ & $1.80 \pm 0.43$ & 0.014 \\
DWI & $0 \pm 0$ & $0.13 \pm 0.13$ & $1.47 \pm 0.45$ & NS \\
Watershed & & & & \\
$\quad$ region (W) & & & & \\
T1W & $0 \pm 0$ & $0.50 \pm 0.27$ & $2.10 \pm 0.51$ & 0.028 \\
PDW & $0 \pm 0$ & $0.13 \pm 0.13$ & $1.80 \pm 0.54$ & 0.030 \\
T2W & $0 \pm 0$ & $0.50 \pm 0.27$ & $2.10 \pm 0.51$ & 0.009 \\
DWI & $0 \pm 0$ & $0.38 \pm 0.26$ & $2.00 \pm .55$ & 0.024 \\
BG \& W & & & & \\
combined & & & & \\
T1W & $0 \pm 0$ & $0.13 \pm 0.13$ & $1.80 \pm 0.41$ & 0.017 \\
PDW & $0 \pm 0$ & $0.00 \pm 0.00$ & $1.75 \pm 0.42$ & 0.006 \\
T2W & $0 \pm 0$ & $0.13 \pm 0.13$ & $1.68 \pm 0.41$ & 0.010 \\
DWI & $0 \pm 0$ & $0.13 \pm 0.13$ & $1.29 \pm 0.43$ & NS \\
\hline
\end{tabular}

T1W, T1-weighted imaging; PDW, proton density-weighted imaging; T2W, T2-weighted imaging; DWI, diffusion-weighted imaging.

*Scoring system based on Barkovitch et al. (10).

$\dagger$ Kruskal-Wallis test. Statistical comparisons were between asphyxiated neonates who received opioid and neonates who did not receive opioid. neonates were exposed to significantly fewer TDPs on DOL 1 (an average of eight TDPs) and over the first 4 DOL $(p<$ $0.05)$ compared with asphyxiated neonates. For asphyxiated neonates, the type and incidence of TDPs for DOL 1 includes an average of one endotracheal intubation, four endotracheal suctioning, one umbilical arterial and/or venous placement, one peripheral intravenous placement, one intramuscular injection, four heelsticks, one orogastric tube placement, one peripheral venipuncture, and either a lumbar puncture, chest tube placement, or urinary catheterization. There were statistically significant correlations between TDP incidence on DOL 1 and 1-min Apgar $(r=-0.63, p<0.0001), 5$-min Apgar $(r=-0.48, p=0.012)$, initial $\mathrm{pH}\left(\chi^{2}, r=-0.40\right.$, $p=0.04)$, base deficit $(r=-0.40, p=0.049)$ and $\mathrm{HCO}_{3}$ concentration $(r=0.41, p=0.03)$. Overall, opioid-treated neonates experienced more TDPs than non-opioid treated neonates, so that in the first 4 DOL, neonates in the opioidtreated group were exposed to 34 TDPs, whereas non-opioidtreated neonates had undergone 27 TDPs.

Correlation between TDPs and brain metabolite measurements in neonates whose MRS was acquired in the first 4 DOL. MRS was acquired early (within the first $4 \mathrm{DOL}$ ) in eight neonates (five nonopioid treated, two opioid treated, and one control). A separate analysis of these data was performed to determine which metabolites were affected most during the time of painful stimuli as no significant differences were found when the entire data set was included. As shown in Table 6, a higher TDP incidence was associated with increased $\mathrm{Cho} / \mathrm{Cr}$ (BG) and higher Glx/Cr (OGM, BG) $(p=0.02)$. A higher incidence of TDPs was also strongly correlated with decreased 
Table 4. Significant correlations between MRI scores and MRSI from BG and TH

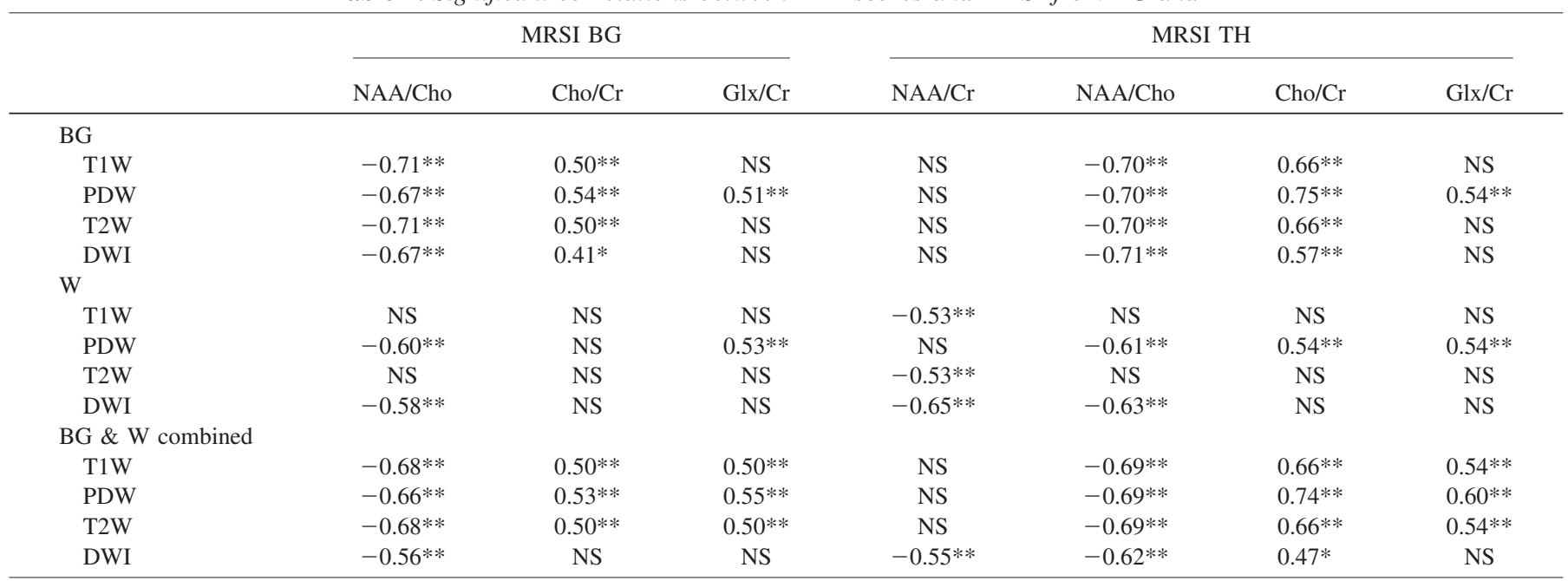

No significant correlations were found between BG NAA/Cr and MRI scores.

Spearman's rho. $* p \leq 0.02 ; * * p \leq 0.005$.

Ins $(p=0.01)$ and $\mathrm{Cr}(p=0.03)$ in OGM and decreased NAA/Cho $(p=0.01)$ in BG on DOL 2 (Table 6).

Brain metabolite levels and ratios from the watershed region. We found statistically significant group differences for NAA, Glx, Cho/Cr, Lac, NAA/Cho, and NAA/Cr (Table 7). Post hoc analysis of quantitative measurements revealed that metabolites such as NAA, Ins, Glx, and NAA/Cho were lower in nontreated asphyxiated neonates compared with controls in short TE MRS. SVS (TE $=144 \mathrm{~ms})$ revealed significant decreases in NAA/Cho ratios in asphyxiated neonates compared with controls $(p=0.02)$. More importantly, we found that the NAA/Cr ratio was reduced $(p=0.03)$ in non-opioidtreated neonates and Lac was not detectable in any control or opioid-treated neonates compared with $40 \%$ of non-opioidtreated patients $(p=0.034)$.

Table 5. Significant correlations between MRI scores and SVS from $O G M$

\begin{tabular}{|c|c|c|c|c|c|}
\hline & \multicolumn{5}{|c|}{ Single-voxel MRS-OGM } \\
\hline & \multicolumn{3}{|c|}{ TE $(20 \mathrm{~ms})$} & \multicolumn{2}{|c|}{ TE (144 ms) } \\
\hline & NAA & $\mathrm{Cr}$ & $\mathrm{Lac}$ & $\mathrm{NAA} / \mathrm{Cr}$ & NAA/Cho \\
\hline \multicolumn{6}{|l|}{ BG } \\
\hline T1W & $-0.56 \dagger$ & $-0.51 \dagger$ & $0.61 \dagger$ & $-0.57 \dagger$ & NS \\
\hline PDW & $-0.50 \dagger$ & NS & $0.67 \dagger$ & $-0.61 \dagger$ & $-0.64 \dagger$ \\
\hline $\mathrm{T} 2 \mathrm{~W}$ & $-0.54 \dagger$ & NS & $0.61 \dagger$ & $-0.56 \dagger$ & $-0.60 \dagger$ \\
\hline DWI & $-0.50 \dagger$ & NS & $0.64 \dagger$ & NS & $-0.58 \dagger$ \\
\hline \multicolumn{6}{|c|}{$\mathrm{W}$ region } \\
\hline T1W & $-0.59 \dagger$ & $-0.59 \dagger$ & $0.56 \dagger$ & NS & NS \\
\hline PDW & NS & $-0.50 \dagger$ & $0.67 \dagger$ & $-0.59 \dagger$ & $-0.51 \dagger$ \\
\hline $\mathrm{T} 2 \mathrm{~W}$ & $-0.56 \dagger$ & $-0.59 \dagger$ & $0.56 \dagger$ & NS & NS \\
\hline DWI & $-0.65 \dagger$ & $-0.61 \dagger$ & $0.63 \dagger$ & $-0.54 \dagger$ & $-0.50^{*}$ \\
\hline \multicolumn{6}{|c|}{$\begin{array}{l}\text { BG \& W } \\
\quad \text { combined }\end{array}$} \\
\hline $\mathrm{T} 1 \mathrm{~W}$ & $-0.52 \dagger$ & NS & $0.62 \dagger$ & $-0.58 \dagger$ & $-0.50^{*}$ \\
\hline PDW & NS & NS & $0.67 \dagger$ & $-0.63 \dagger$ & $-0.55 \dagger$ \\
\hline $\mathrm{T} 2 \mathrm{~W}$ & NS & NS & $0.56 \dagger$ & $-0.53 \dagger$ & NS \\
\hline DWI & NS & NS & $0.66 \dagger$ & NS & NS \\
\hline
\end{tabular}

Spearman's $\rho$ correlation coefficient.

$* p \leq 0.01 ; \dagger p \leq 0.005$.
Brain metabolite ratios from the $B G$ and $T H$. MRSI through the BG and TH was completed in five of eight opioid-treated neonates and 18 of 20 non-opioid-treated neonates (Table 8). MRSI was not completed in some patients because they awoke during the study. MRSI metabolites were not significantly different between opioid-treated and control neonates except for NAA/Cho $(p=0.022)$. However, significant differences were noted between non-opioid-treated and control neonates for all metabolites except for $\mathrm{Cho} / \mathrm{Cr}$ and Glx/Cr (BG and TH) (Table 8). No significant metabolite differences were found between opioid-treated and nontreated asphyxiated neonates in the $\mathrm{BG}$ and $\mathrm{TH}$, and Lac was detectable in nearly equal percentages in these regions. Shown in Fig. 3 are spectra from neonates with mild, moderate, and severe hypoxic-ischemic encephalopathy.

\section{DISCUSSION}

The two principal findings in the current study are that (1) the high number of TDPs seen in asphyxiated newborns in the first 4 DOL correlated with spectral changes suggestive of brain injury (i.e. elevated $\mathrm{BG} \mathrm{Cho} / \mathrm{Cr}$ and $\mathrm{Glx} / \mathrm{Cr}$, reduced

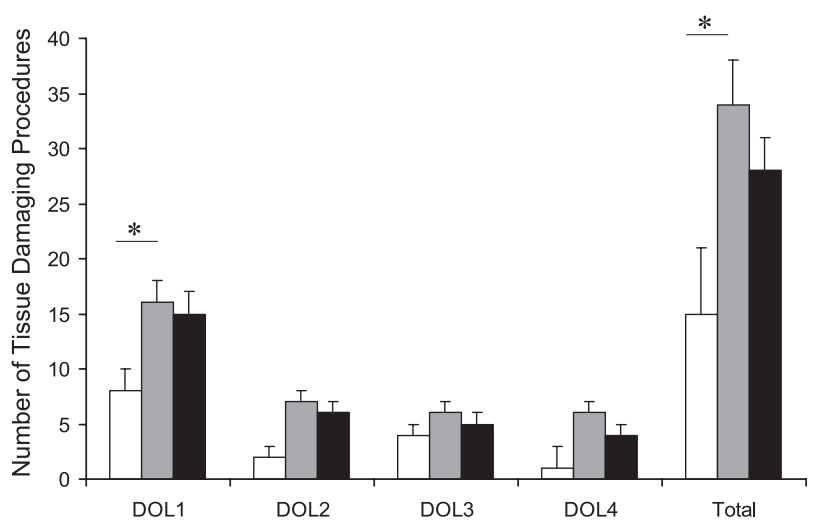

Figure 4. Number of TDPs in the first 4 DOL. Control neonates (open columns), neonates who received opioid (shaded columns), and neonates who did not receive opioid (filled columns). 
Table 6. Spearman correlation between number of TDPS and SVS $(O G M)$ and MRSI $(B G)$ in neonates whose MRS examination occurred at DOL 4 or earlier ( $n=8$, five nonopioid treated, two opioid treated, and one control)

\section{No. of TDPs}

DOL $1 \quad$ DOL $2 \quad$ DOL $3 \quad$ DOL 4

\begin{tabular}{lcccc}
\hline SVS $(\mathrm{OGM}, \mathrm{TE}=20 \mathrm{~ms})$ & & & & \\
Cr $(\mathrm{mM})$ & & & \\
$\quad$ Correlation coefficient & $\mathrm{NS}$ & -0.75 & $\mathrm{NS}$ & $\mathrm{NS}$ \\
$\quad p$ & & 0.03 & & \\
Ins $(\mathrm{mM})$ & & & & \\
$\quad$ Correlation coefficient & $\mathrm{NS}$ & -0.84 & $\mathrm{NS}$ & $\mathrm{NS}$ \\
$\quad p$ & & 0.009 & & \\
Glx/Cr & & & & \\
$\quad$ Correlation coefficient & $\mathrm{NS}$ & 0.81 & $\mathrm{NS}$ & $\mathrm{NS}$ \\
$\quad p$ & & 0.02 & & \\
MRSI (BG, TE $=144 \mathrm{~ms})$ & & & & \\
NAA/Cho & & & & \\
$\quad$ Correlation coefficient & $\mathrm{NS}$ & -0.90 & $\mathrm{NS}$ & $\mathrm{NS}$ \\
$\quad p$ & & 0.002 & & \\
Cho/Cr & & & & \\
$\quad$ Correlation coefficient & 0.79 & 0.76 & $\mathrm{NS}$ & $\mathrm{NS}$ \\
$\quad p$ & 0.02 & 0.02 & & \\
Glx/Cr & & & & \\
$\quad$ Correlation coefficient & 0.79 & 0.85 & NS & 0.87 \\
$p$ & 0.03 & 0.01 & & 0.01 \\
\hline
\end{tabular}

OGM Cr and Ins, reduced NAA/Cho in BG) $(17,18)$ and (2) opioid-treated infants had evidence of reduced brain injury as determined by higher NAA/Cr (OGM) ratios and no evidence of Lac (OGM) than non-opioid-treated neonates. Together these findings suggest that TDPs may increase the amount of neonatal pain and stress augmenting neonatal brain injury associated with hypoxia-ischemia and that opioids used to treat pain do not have a harmful effect and may be neuroprotective.

TDPs and spectral metabolite changes. The asphyxiated term neonates in our study were exposed to an increased number of TDPs (15 on DOL 1, 34 by DOL 4) compared with controls. Although pain scores were not obtained, these procedures are known to result in pain and stress. In neonates whose MRS was obtained by DOL 4, we found that increased incidence of TDPs correlated with decreased $\mathrm{Cr}$ and $\mathrm{Ins}$ in the OGM and increased $\mathrm{Cho} / \mathrm{Cr}$ in the $\mathrm{BG}$, suggesting that exposure to pain and stress may contribute to altered brain metabolism (reduced $\mathrm{Cr}$ ) and membrane disruption (increased Cho/ $\mathrm{Cr}$ ). Although lower $\mathrm{Cr}$ signal could represent overall tissue loss and other pathologies, the significant correlation between TDPs and OGM creatine may also reflect the vulnerability of the neonatal brain to excessive neuronal stimulation during a period of secondary energy failure when adenosine triphosphate levels are already at a minimum. Reduced Ins in response to chronic pain has been described previously in adults (19), whereas an increase in Ins has been observed in neonates with asphyxial brain injury (20). Alternatively, other factors such as overall brain tissue loss and relaxation time changes may also affect metabolite levels.

We also found a significant correlation between increased $\mathrm{Glx} / \mathrm{Cr}$ ratios (OGM, BG) and increased incidence of TDPs in the first 4 DOL. The increased Glx/Cr ratio in the OGM, however, is not due to increased Glx levels but rather reduction of $\mathrm{Cr}$ to a greater extent than Glx (Table 7). Although increased Glx signals have been reported in older pediatric patients after hypoxic-ischemic injury (21) and trauma (13), Roelants-van-Rijn et al. (22) were not able to show changes in Glx ratios after hypoxic-ischemic injury in neonates. The difference in findings may be attributed to the age of the patients at the time of the study. As described by Pellerin and colleagues (23), present in the immature brain is an alternative energy pathway in which astrocytes take up glutamate for conversion to glutamine, which in turn stimulates glycolysis within the astrocyte. Glycolysis produces Lac, which is then taken up by neurons to metabolize into energy. It is possible that the neonatal brain uses this alternative energy source. This would explain the presence of increased Lac as well as decreased levels of Glx as shown in our study (Table 7). The removal of

Table 7. SVS mean metabolite data from OGM

\begin{tabular}{|c|c|c|c|c|c|c|}
\hline & $\begin{array}{l}\text { Control } \\
(n=6)\end{array}$ & $\begin{array}{l}\text { Received opioid } \\
\quad(n=8)\end{array}$ & $\begin{array}{l}\text { No opioid } \\
(n=20)\end{array}$ & $\begin{array}{c}\text { Control vs } \\
\text { opioid: } p^{*} \text { value }\end{array}$ & $\begin{array}{c}\text { Control } v s \\
\text { no opioid: } p^{*} \text { value }\end{array}$ & $\begin{array}{c}\text { Opioid } v s \\
\text { no opioid: } p^{*} \text { value }\end{array}$ \\
\hline \multicolumn{7}{|l|}{ TE $(20 \mathrm{~ms})$} \\
\hline NAA (mM) & $5.27 \pm 0.41$ & $4.28 \pm 0.32$ & $3.51 \pm 0.40$ & NS & 0.019 & NS \\
\hline Cho (mM) & $5.23 \pm 0.43$ & $5.31 \pm 0.32$ & $4.50 \pm 0.39$ & NS & NS & NS \\
\hline Ins (mM) & $8.46 \pm 0.83$ & $6.91 \pm 0.48$ & $5.99 \pm 0.66$ & NS & 0.044 & NS \\
\hline Glx (mM) & $14.24 \pm 1.42$ & $10.25 \pm 0.49$ & $10.31 \pm 0.57$ & 0.006 & 0.003 & NS \\
\hline NAA/Cho & $1.03 \pm 0.09$ & $0.82 \pm 0.06$ & $0.75 \pm 0.07$ & NS & 0.021 & NS \\
\hline $\mathrm{Cho} / \mathrm{Cr}$ & $1.27 \pm 0.07$ & $1.62 \pm 0.08$ & $1.65 \pm 0.21$ & NS & NS & NS \\
\hline $\mathrm{Ins} / \mathrm{Cr}$ & $2.05 \pm 0.14$ & $2.09 \pm 0.10$ & $1.80 \pm 0.13$ & NS & NS & NS \\
\hline $\mathrm{Glx} / \mathrm{Cr}$ & $3.47 \pm 0.24$ & $3.14 \pm 0.18$ & $3.32 \pm 0.32$ & NS & NS & NS \\
\hline \multicolumn{7}{|l|}{$\mathrm{TE}(144 \mathrm{~ms})$} \\
\hline $\mathrm{NAA} / \mathrm{Cr}$ & $1.28 \pm 0.07$ & $1.20 \pm 0.13$ & $0.97 \pm 0.07$ & NS & NS & NS \\
\hline
\end{tabular}

*One-way ANOVA with Fisher's LSD and Tukey's HSD tests.

$\lceil$ Lac presence reported in this row was confirmed using TE $=144 \mathrm{~ms}$ spectra for all patients.

$\ddagger$ Chi-square test. 
Table 8. MRSI mean metabolite ratios from $B G$ and $T H$

\begin{tabular}{|c|c|c|c|c|c|c|}
\hline & $\begin{array}{l}\text { Control } \\
(n=8)\end{array}$ & $\begin{array}{l}\text { Received opioid } \\
\quad(n=5)\end{array}$ & $\begin{array}{l}\text { No opioid } \\
(n=18)\end{array}$ & $\begin{array}{c}\text { Control vs } \\
\text { opioid: } p^{*} \text { value }\end{array}$ & $\begin{array}{c}\text { Control vs } \\
\text { no opioid: } p^{*} \text { value }\end{array}$ & $\begin{array}{c}\text { Opioid } v s \\
\text { no opioid: } p^{*} \text { value }\end{array}$ \\
\hline \multicolumn{7}{|l|}{ BG } \\
\hline $\mathrm{NAA} / \mathrm{Cr}$ & $1.10 \pm 0.03$ & $0.89 \pm 0.06$ & $0.91 \pm 0.04$ & NS & 0.007 & NS \\
\hline $\mathrm{Cho} / \mathrm{Cr}$ & $1.46 \pm 0.09$ & $1.49 \pm 0.10$ & $1.87 \pm 0.16$ & NS & NS & NS \\
\hline $\mathrm{Glx} / \mathrm{Cr}$ & $0.17 \pm 0.03$ & $0.24 \pm 0.05$ & $0.37 \pm 0.09$ & NS & NS & NS \\
\hline Lac presence & $0 \%$ & $40 \%$ & $44 \%$ & NS & $0.023 \dagger$ & NS \\
\hline NAA/Cho & $0.78 \pm 0.04$ & $0.65 \pm 0.03$ & $0.53 \pm 0.04$ & NS & $<0.001$ & NS \\
\hline $\mathrm{Cho} / \mathrm{Cr}$ & $1.45 \pm 0.12$ & $1.46 \pm 0.08$ & $2.01 \pm 0.23$ & NS & NS & NS \\
\hline $\mathrm{Glx} / \mathrm{Cr}$ & $0.16 \pm 0.03$ & $0.20 \pm 0.04$ & $0.30 \pm 0.05$ & NS & NS & NS \\
\hline Lac presence & $0 \%$ & $40 \%$ & $38 \%$ & NS & $0.039 \dagger$ & NS \\
\hline
\end{tabular}

NS, not significant.

*One-way ANOVA with Fisher's LSD and Tukey's HSD tests.

$\dagger$ Chi-square test.

glutamate from the extracellular space would also serve to protect surrounding cells from excitotoxicity.

It is unknown whether the increased $\mathrm{Glx} / \mathrm{Cr}$ ratios seen in the BG in this study are also due to a reduction of $\mathrm{Cr}$ or rather to an increase in Glx. Other studies have also reported increased Glx ratios in the BG and $\mathrm{TH}$ of neonates after severe hypoxic-ischemic injury $(6,24)$. The rationale behind a regional difference is uncertain but could be related to earlier maturation of the BG and $\mathrm{TH}$ compared with the cortex, higher levels of metabolic activity in this subcortical gray matter region, or perhaps to the fact that the BG express high levels of opioid receptors (25). A quantitative MRS study would be helpful to determine Glx changes in the BG and TH.

Opioids and spectral metabolite changes. As previously noted, we have reported that asphyxiated term neonates treated with opioids during the first week of life had significantly less brain injury in the $\mathrm{BG}$ and $\mathrm{W}$ regions as assessed by MRI scores and had better long-term neurologic outcomes as assessed by PCPCS scores (4). The current study extends these observations as we also found that asphyxiated neonates treated with opioids showed significantly higher mean NAA/Cr measured quantitatively at short TE and did not have Lac in OGM compared with neonates who did not receive opioids (Table 7). However, except for NAA/Cr and presence of Lac in OGM, brain metabolites were similar between opioid- and non-opioid-treated groups. No significant differences were seen between treated and nontreated neonates in the $\mathrm{BG}$ and $\mathrm{TH}$. These measurements taken at TE $144 \mathrm{~ms}$, however, were limited in ability to detect Glx and were reported as ratios because they were not quantitatively analyzed. Caution is warranted regarding interpretation of these findings because of these and other important study limitations such as the small sample size, retrospective study design, and the reduced number of infants available for long-term follow-up and possible selection bias.

Considering the study limitations, the data suggest that asphyxiated neonates treated with opioids have less brain injury and better outcomes. Several explanations for a neuroprotective effect of opioids have been suggested in the literature. Opioids are known to stimulate inwardly rectifying potassium channels leading to hyperpolarization (26). Opioids are also documented to alter peripheral and central temperature in a number of species including humans $(27,28)$. This is especially relevant because of current clinical trials documenting hypothermia's neuroprotective effects. Last, cardiac and cerebellar Purkinje cells treated with morphine had less injury and higher levels of survival than nontreated control cells $(29,30)$. The postulated mechanism involves the activation of $\delta_{1}$-opioid receptors, which triggers a signal transduction pathway that decreases calcium influx, increases potassium efflux through activation of adenosine trisphosphate-sensitive potassium $\left(\mathrm{K}_{\mathrm{ATP}}\right)$ channels (31) leading to neuronal hyperpolarization. Additional prospective studies are needed to further evaluate the potentially neuroprotective role of opioids in asphyxiated term neonates.

\section{REFERENCES}

1. Shalak L, Perlman JM 2004 Hypoxic-ischemic brain injury in the term infant-current concepts. Early Hum Dev 80:125-141

2. Cady EB 2001 Magnetic resonance spectroscopy in neonatal hypoxic-ischaemic insults. Childs Nerv Syst 17:145-149

3. Rutherford M 2002 MRI of the Neonatal Brain. WB Saunders, London, pp 295-308

4. Angeles DM, Wycliffe N, Michelson D, Holshouser BA, Deming DD, Pearce WJ, Sowers LC, Ashwal S 2005 Use of opioids in asphyxiated term neonates: effects on neuroimaging and clinical outcome. Pediatr Res 57:873-878

5. Dempsey EM, Al Hazzani F, Faucher D, Barrington KJ 2006 Facilitation of neonatal endotracheal intubation with mivacurium and fentanyl in the neonatal intensive care unit. Arch Dis Child Fetal Neonatal Ed 91:F279-F282

6. Anand KJ, Scalzo FM 2000 Can adverse neonatal experiences alter brain development and subsequent behavior? Biol Neonate 77:69-82

7. Porter FL, Wolf CM, Miller JP 1999 Procedural pain in newborn infants: the influence of intensity and development. Pediatrics 104:e13

8. Lorek A, Takei Y, Cady EB, Wyatt JS, Penrice J, Edwards AD, Peebles D, Wylezinska M, Owen-Reece H, Kirkbride V, et al 1994 Delayed ("secondary") cerebral energy failure after acute hypoxia-ischemia in the newborn piglet: continuous 48 -hour studies by phosphorus magnetic resonance spectroscopy. Pediatr Res 36:699-706

9. Azzopardi D, Wyatt JS, Cady EB, Delpy DT, Baudin J, Stewart AL, Hope PL, Hamilton PA, Reynolds EO 1989 Prognosis of newborn infants with hypoxicischemic brain injury assessed by phosphorus magnetic resonance spectroscopy. Pediatr Res 25:445-451

10. Barkovich AJ, Hajnal BL, Vigneron D, Sola A, Partridge JC, Allen F, Ferriero DM 1998 Prediction of neuromotor outcome in perinatal asphyxia: evaluation of MR scoring systems 1998. AJNR Am J Neuroradiol 19:143-149

11. Pu Y, Li QF, Zeng CM, Gao J, Qi J, Luo DX, Mahankali S, Fox PT, Gao JH 2000 Increased detectability of alpha brain glutamate/glutamine in neonatal hypoxicischemic encephalopathy. AJNR Am J Neuroradiol 21:203-212

12. Provencher SW 1993 Estimation of metabolite concentrations from localized in vivo proton NMR spectra. Magn Reson Med 30:672-679 
13. Ashwal S, Holshouser B, Tong K, Serna T, Osterdock R, Gross M, Kido D 2004 Proton MR spectroscopy detected glutamate/glutamine is increased in children with traumatic brain injury. J Neurotrauma 21:1539-1552

14. Ashwal S, Holshouser BA, Tomasi LG, Shu S, Perkin RM, Nystrom GA, Hinshaw DB Jr 1997 1H-magnetic resonance spectroscopy-determined cerebral lactate and poor neurological outcomes in children with central nervous system disease. Ann Neurol 41:470-481

15. Fiser DH 1992 Assessing the outcome of pediatric intensive care. J Pediatr 121:68-74

16. Fiser DH, Long N, Roberson PK, Hefley G, Zolten K, Brodie-Fowler M 2000 Relationship of pediatric overall performance category and pediatric cerebral performance category scores at pediatric intensive care unit discharge with outcome measures collected at hospital discharge and 1- and 6-month follow-up assessments. Crit Care Med 28:2616-2620

17. Shu SK, Ashwal S, Holshouser BA, Nystrom G, Hinshaw DB Jr 1997 Prognostic value of 1H-MRS in perinatal CNS insults. Pediatr Neurol 17:309-318

18. Barkovich AJ, Baranski K, Vigneron D, Partridge JC, Hallam DK, Hajnal BL, Ferriero DM 1999 Proton MR spectroscopy for the evaluation of brain injury in asphyxiated, term neonates. AJNR Am J Neuroradiol 20:1399-1405

19. Pattany PM, Yezierski RP, Widerstrom-Noga EG, Bowen BC, Martinez-Arizala A, Garcia BR, Quencer RM 2002 Proton magnetic resonance spectroscopy of the thalamus in patients with chronic neuropathic pain after spinal cord injury. AJNR Am J Neuroradiol 23:901-905

20. Robertson NJ, Lewis RH, Cowan FM, Allsop JM, Counsell SJ, Edwards AD, Cox IJ 2001 Early increases in brain myo-inositol measured by proton magnetic resonance spectroscopy in term infants with neonatal encephalopathy. Pediatr Res 50:692-700

21. Kreis R, Arcinue E, Ernst T, Shonk T, Flores R, Ross B 1996 Hypoxic encephalopathy after near-drowning studied by quantitative $1 \mathrm{H}$-magnetic resonance spectroscopy. J Clin Invest 97:1142-1154
22. Roelants-Van Rijn AM, Van Der Grond J, De Vries L, Groenendaal F 2001 Value of 1HMRS using different echo times in neonates with cerebral hypoxia-ischemia. Pediatr Res 49:356-362

23. Pellerin L, Pellegri G, Bittar P, Charnay Y, Bouras C, Martin J, Stella N, Magistrett P 1998 Evidence supporting the existence of an activity-dependent astrocyte-neuron lactate shuttle. Dev Neurosci 20:291-299

24. Groenendaal F, Roelants-Van Rijn AM, van Der Grond J, Toet MC, de Vries LS 2001 Glutamate in cerebral tissue of asphyxiated neonates during the first week of life demonstrated in vivo using proton magnetic resonance spectroscopy. Biol Neonate 79:254-257

25. Wang H, Gracy KN, Pickel VM 1999 Mu-opioid and NMDA-type glutamate receptors are often colocalized in spiny neurons within patches of the caudateputamen nucleus. J Comp Neurol 412:132-146

26. Ocana M, Cendan CM, Cobos EJ, Entrena JM, Baeyens JM 2004 Potassium channels and pain: present realities and future opportunities. Eur J Pharmacol 500:203-219

27. Su CF, Liu MY, Lin MT 1987 Intraventricular morphine produces pain relief, hypothermia, hyperglycaemia and increased prolactin and growth hormone levels in patients with cancer pain. J Neurol 235:105-108

28. Adler MW, Geller EB, Rosow CE, Cochin J 1988 The opioid system and temperature regulation. Annu Rev Pharmacol Toxicol 28:429-449

29. McPherson BC, Yao Z 2001 Signal transduction of opioid-induced cardioprotection in ischemia-reperfusion. Anesthesiology 94:1082-1088

30. Peart JN, Gross ER, Gross GJ 2005 Opioid-induced preconditioning: recent advances and future perspectives. Vascul Pharmacol 42:211-218

31. Barry U, Zuo Z 2005 Opioids: old drugs for potential new applications. Curr Pharm Des 11:1343-1350 